\title{
A FORMAÇÃO PROFISSIONAL DO TÉCNICO EM QUÍMICA: CARACTERIZAÇÃO DAS ORIGENS E NECESSIDADES ATUAIS
}

\author{
Luciane Terezinha Joly Matsumoto* e Izaura Hiroko Kuwabara \\ Departamento de Química, Setor de Ciências Exatas, Universidade Federal do Paraná, CP 19081, 81531-990 Curitiba - PR
}

Recebido em 5/1/04; aceito em 22/6/04; publicado na web em 5/11/04

\begin{abstract}
THE PROFESSIONAL FORMATION OF THE TECHNICIAN IN CHEMISTRY: CHARACTERIZATION OF ITS ORIGINS AND CURRENT NECESSITIES. This work reports the situation of technicians employed in chemical industries in Curitiba city, working in chemistry and related fields. The aim of this study is to characterize not only their work conditions, but also their social, economic, professional and educational profiles.
\end{abstract}

Keywords: chemistry technician; education and labour; professional education.

\section{INTRODUÇÃO}

Este trabalho tem origem na dissertação de mestrado intitulada "A reestruturação do mundo do trabalho e a formação profissional do técnico em química", desenvolvida no Programa de Pós-graduação em Educação (PPGE) do Setor de Educação da Universidade Federal do Paraná. O artigo objetiva contribuir com novos conhecimentos sobre o campo de atuação do técnico químico de nível médio, verificando os impactos da reestruturação produtiva nas atividades, na carreira e na formação desses profissionais.

As modificações ocorridas no mundo do trabalho, referentes a muitas questões atualmente colocadas no panorama mundial, como a globalização, a produção flexível e as novas demandas do mercado de trabalho, exigem adequação do perfil profissional impactando diretamente na formação profissional.

Este processo de modificações tornou-se necessário para garantir a manutenção do sistema capitalista, pois o sistema organizacional anterior (taylorista-fordista) já mostrava sinais de esgotamento, não permitindo a ampliação da extração da mais valia e, conseqüentemente, da lucratividade. À medida que os meios de produção vão se modificando há a necessidade de mudar também o sistema organizacional para que este permita cada vez mais ampliar a produção, em menor tempo, a menores custos e, assim, aumentando a extração da mais valia. O conjunto de modificações e estratégias organizacionais necessárias para adequar os novos meios de produção, a mão-de-obra e a ampliação da extração de mais valia denomina-se reestruturação produtiva ${ }^{1}$.

O modelo de produção taylorista-fordista desenvolvido nos Estados Unidos no início do século XX, inicialmente na indústria automotiva por Henry Ford, consiste na produção em massa, padronizada $^{2}$. A produção padronizada permite a completa intercambialidade das partes e simplicidade no processo de montagem, o que possibilitou uma produção em larga escala, a menores custos, em menor espaço de tempo e com melhor qualidade do que na era da produção manual. No modo de produção taylorista-fordista o operário realiza apenas tarefas fragmentadas, nas quais repete inúmeras vezes a mesma função, e assim obtém uma maior destreza e, deste modo, propicia ao longo do tempo maior produtividade em menor espaço de tempo. Deste modo o trabalhador dominava somente uma

*e-mail: lucianej@tutopia.com.br etapa restrita da produção, diferente da produção manual que exigia o domínio de todo o processo de produção.

O trabalhador fordista, apesar de estar sendo explorado, de realizar tarefas repetitivas, podia ter condições de existência com o mínimo de conforto, propiciadas pelo emprego com alguma estabilidade, decorrente da escassez de mão-de-obra qualificada e da forte organização sindical. A presença do Estado (Estado de Bem Estar Social) garantindo o suprimento das necessidades sociais aliada à estabilidade garantiam que ele produzisse o máximo possível mas também consumisse muito, fazendo a engrenagem do capital girar.

Este modelo já não estava mais sendo adequado à reprodução do capital, portanto, deu-se um processo de reestruturação produtiva. Deste modo esta reestruturação foi conseqüência da crise do Estado de Bem Estar Social, da necessidade de novos meios de produção e da superação do fordismo pelo capitalismo ${ }^{3}$.

A crise do Estado de Bem Estar Social deve-se às reduções de investimentos do Estado em educação, saúde, habitação e previdência social, assim o poder de consumo do trabalhador diminui, pois o gasto com a manutenção dessas necessidades básicas, anteriormente supridas pelo Estado, reduz sua capacidade de compra, rompendo o ciclo da produção fordista.

A partir de 1973, com o início da crise, houve um aumento da exploração do trabalhador e uma diminuição das condições de trabalho, menores salários. Estas condições propiciaram a integração da força produtiva feminina, de negros e de imigrantes já que estes constituíam classes desorganizadas e não sindicalizadas, o que facilitava sua submissão a condições precárias de emprego e salário.

A crise estrutural do capitalismo originou-se devido a vários fatores, entre eles o grande acúmulo de capital proveniente das fusões comerciais entre as empresas; queda das taxas de lucro devido ao aumento do preço da força de trabalho; esgotamento do acúmulo e da produção taylorista-fordista; retração do consumo devido aos altos níveis de desemprego; a crise do Estado de Bem Estar Social, que passou muitas das obrigações do Estado para o privado, no intuito de diminuir gastos e o aumento acentuado de privatizações, desregulamentações e flexibilizações de mercado, do processo produtivo e da força de trabalho ${ }^{3}$.

Tendo em vista todo este quadro da crise estrutural capitalista, iniciou-se um processo de reorganização na tentativa de retomar os patamares da expansão. Para isso houve um intenso processo de reestruturação da produção e do trabalho, desregulamentação dos direitos trabalhistas desmonte do sistema produtivo estatal. $\mathrm{O}$ 
neoliberalismo e a era Thatcher-Reagan trouxeram suportes para todo esse movimento do capital ${ }^{3}$.

Com o intuito de aumentar a extração da mais valia, as organizações passam a utilizar outras formas de gestão organizacional tratando, mesmo que em nível de discurso, os operários como pessoas com necessidades complexas, tanto fisiológicas quanto sociais e psicológicas. Para satisfazer suas necessidades sociais no trabalho as novas organizações buscaram oportunizar o crescimento e a integração dos indivíduos, o desenvolvimento de funções mais enriquecedoras levando a níveis maiores de criatividade e inovação e, assim, possibilitando uma performance mais adequada no trabalho desses operários, aumentando sua produtividade.

Com a reestruturação os capitalistas perceberam que, além de explorar a força de trabalho muscular dos operários, poderiam também explorar sua força de trabalho intelectual, o que não era possível em um sistema de produção taylorista-fordista. Nesta fase as empresas implementaram o toyotismo, a qualidade total, as formas de acumulação flexível (não mais restritas à produção), formas de gestão organizacional e o avanço tecnológico, para poderem aumentar a exploração do trabalho humano ${ }^{3}$.

O novo modelo toyotista iniciou-se a partir de 1950, quando o engenheiro japonês Eiji Toyoda realizou uma visita de 3 meses às instalações da Ford em Detroit. Com base nas suas observações, Toyoda e Taiichi Ohno concluíram que não seria possível implementar o sistema de produção em massa no Japão, devido à escassez de espaços para acomodar os grandes estoques e, deste modo, nasceu o Sistema Toyota de produção ou Sistema de Produção Flexível ${ }^{2}$.

Este novo modelo tem como características a produção em pequena escala de produtos que se apresentam com pequenas variações e diferenças entre si, possibilitando atender às diferentes necessidades dos consumidores.

Há também a fragmentação da classe trabalhadora, precarização e terceirização da força humana de trabalho, destruição do sindicalismo de classe substituído por um sindicato de empresa. Todo este processo de reestruturação produtiva do capital fornece a base do projeto ideológico-político neoliberal ${ }^{3}$.

As relações existentes entre a estrutura escolar e as exigências do mercado evidenciam o quanto a escola, em nossa sociedade, é responsável pela formação e adequação desses alunos para atuarem em uma determinada realidade, segundo um determinado momento histórico. Assim, uma análise da escola como aparelho ideológico ${ }^{4}$ e a análise das origens do ensino profissional no Brasil podem ser apropriadas para ajudar a entender como se deu o desenvolvimento do ensino técnico.

Foi realizado o levantamento de todas as implicações da reestruturação do mundo do trabalho sobre o técnico químico, em sua atuação profissional, como a natureza das atividades realizadas, a caracterização da profissão pelo Ministério do Trabalho através da Classificação Brasileira das Ocupações ${ }^{5}$ (CBO).

\section{A ESCOLA E A DUALIDADE ESTRUTURAL}

Com o nascimento da propriedade individual surge a divisão do trabalho, já que uma determinada propriedade torna-se exclusiva de um indivíduo ou de um grupo, distinguindo-os entre si pelo tipo de posse. A sociedade passa, então, a se dividir em classes e, deste modo, o mundo do trabalho submete-se à divisão social para satisfazer as necessidades do capital, gerando um sistema de metabolismo social e um sistema de mediações ${ }^{3}$.

Na sociedade capitalista na qual a íntima relação Estado e saber origina-se na forma de separação entre o trabalho intelectual e o trabalho manual que se encontra “... diretamente instaurada pelo discurso do Estado e portanto constituindo técnica política para a ocu- pação pelo Estado dos campos de consumo coletivo (transportes, habitação, saúde, assistência social, lazer) em que os poderes ideológico-simbólicos materializados nas produções (habitações, centros culturais etc.) prolongam diretamente as relações estatais, as ligações entre os poderes de classe e o Estado tornam-se cada vez mais estreitas"6 (p. 42 e 43).

Assim, este sistema de mediações é totalmente sustentado pelo Estado através dos vários aparelhos ideológicos e de repressão. Como aparelhos ideológicos podemos exemplificar a escola, os órgãos de comunicação e a igreja; e como aparelhos repressores, o poder judiciário e as forças armadas, entre outros ${ }^{4}$.

Deste modo a Escola não cumpre seu papel social desprovida de intenções, ela foi criada com um propósito maior do que a transmissão de conhecimentos. A escola também objetiva disciplinar as pessoas que por ela passam, de modo que sejam aceitas socialmente, apresentando atitudes e comportamentos socialmente desejados naquele momento histórico.

A escola deverá formar operários minimamente instruídos, preparando o trabalhador o suficiente para o desempenho de sua função e, assim, suprir o mercado com mão-de-obra adequada.

A escola constitui-se como um aparelho ideológico de Estado, mantendo a educação dos indivíduos adequada e regulada pelas necessidades da sociedade, através da intervenção do Estado por meio de suas políticas públicas? ${ }^{7}$.

A origem do ensino profissional no Brasil é fundamentada em necessidades bastante especiais: educar pelo trabalho os órfãos, pobres e desvalidos da sorte, retirando-os das ruas; assim, o Estado ao instituir a formação profissional como política pública o faz na perspectiva moralizadora da formação do caráter pelo trabalho ${ }^{8}$.

Surge no Brasil a formação profissional como responsabilidade do Estado, em 1909, através da instituição de 19 escolas de artes e ofício, sendo estas as precursoras das escolas técnicas federais e estaduais ${ }^{8}$.

A organização do ensino escolar no Brasil foi marcada pela categoria da dualidade estrutural, já que a formação dos trabalhadores e cidadãos passa por trajetórias diferentes, dependendo de quais funções intelectuais ou instrumentais iriam desempenhar.

A escola já se encontrava estruturada e dividida segundo as funções sociais que cada sujeito deveria desempenhar, portanto dividida em classes sociais. A escola para a elite era um ensino propedêutico de cunho generalista; o ensino profissional que se destinava às classes populares atribuia uma conotação de inferioridade ao trabalho manual e, assim, justificava ser destinada à classe trabalhadora operacional $^{9}$.

A presença da dualidade estrutural é clara na sociedade capitalista, cujo desenvolvimento das forças produtivas baseado no modelo taylorista-fordista institui a ruptura entre as atividades de planejamento e supervisão das de execução. Restringem assim o número de cargos destinados aos que irão desempenhar as atividades de planejamento e supervisão e requerem, por outro lado, um grande número de mão-de-obra possuidora somente de sua força de trabalho, não admitindo a universalização do conhecimento.

Com a presença da categoria dualidade estrutural na origem da escola brasileira, presente ainda atualmente, as escolas técnicas sempre destinaram-se a atender as classes menos favorecidas, com um ensino de segunda linha, de baixo custo e marcado por conhecimentos fragmentados. Sob esta óptica inicia-se a formação profissional segundo o ensino técnico ${ }^{10}$.

\section{ENSINO TÉCNICO DE QUÍMICA}

O ensino técnico químico surgiu com a intenção de proporcionar uma formação profisssional na área da Química, mais rápida, para 
suprir o mercado com mão-de-obra com alguma especialidade, a menores custos. Conforme a citação de Siqueira ${ }^{11}$ :

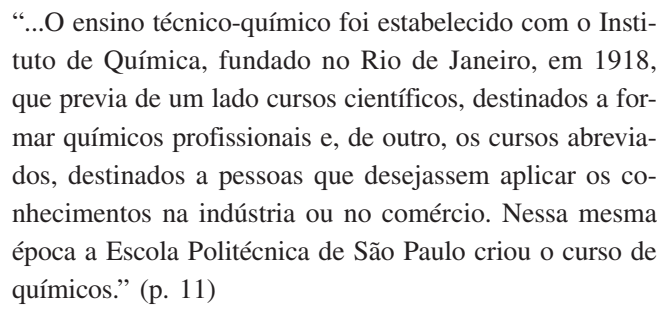

O Centro Estadual de Educação Profissional de Curitiba (CEEP), denominação adotada a partir de 2002 (antigo Instituto Politécnico Estadual-IPE), é atualmente o único estabelicimento responsável pela formação profissional técnica de nível médio da área de química em Curitiba. Após a nova $\mathrm{LDB}^{12}$ que transfere a formação profissional para o pós-médio, a Escola Estadual Francisco Zardo, que também ofertava o curso de técnico em química, encerrou suas atividades em relação à formação profissional em 1999.

O antigo ensino técnico também constituía o Sistema Nacional de Educação, por fazer parte do sistema educacional do país e também estava submetido à legislação nacional, como o ensino médio ${ }^{13}$. $\mathrm{O}$ curso de formação técnica, em tese, voltado para o mercado de trabalho, tinha duração de 4 anos, sendo os 3 primeiros destinados a abranger os conteúdos do Ensino Médio em conjunto aos conteúdos específicos do curso técnico em questão e, o quarto e último ano, direcionado ao estágio prático em empresas e às disciplinas de aplicação direta.

Os programas de química do ensino médio, do ensino profissional em química e do ensino superior de Química possuem praticamente o mesmo conteúdo programático, distribuídos nas disciplinas de Química Geral, Química Orgânica, Química Inorgânica, Química Analítica e Físico-Química. As diferenças encontradas referem-se ao tempo destinado para abordar cada assunto e à priorização de determinados aspectos de cada assunto nos programas dos diferentes níveis de ensino.

O programa de formação profissional do técnico em Química, além de apresentar o mesmo programa do ensino médio regular, apresentava uma grade anual constituída em grande parte por disciplinas de química, maior carga horária de aulas práticas de laboratório e a priorização da abordagem dos aspectos operacionais de cada assunto.

Além dos aspectos citados, o programa do curso Técnico em Química continha praticamente todos os temas tratados no ensino superior, contidos nas disciplinas do Curso de Química, acrescidos de alguns do curso de Engenharia Química. Porém o número de horas para tratar os conteúdos eram menores que os destinados ao nível superior, resultando numa formação mais aligeirada, devido ao grande volume de conteúdos abordados e com ênfase em memorização e reprodução. Assim, o conteúdo de química do ensino técnico é maior que o do ensino médio gerando, conseqüentemente, uma abordagem superficial. Na Tabela 1 encontra-se a distribuição das disciplinas do antigo ensino técnico em química, simultâneo ao Ensino Médio.

O curso técnico em Química era constituído das seguintes disciplinas, além das referentes ao ensino médio: química inorgânica, química analítica qualitativa, química analítica quantitativa, química orgânica, físico-química, corrosão, tecnologia orgânica, tecnologia inorgânica, operações unitárias, organização e normas, higiene e segurança no trabalho.

As disciplinas de corrosão, tecnologia orgânica, tecnologia inorgânica, operações unitárias são disciplinas encontradas no curso
Tabela 1. Distribuição das disciplinas do curso técnico em química ${ }^{14}$ Disciplinas $\quad 1^{\circ}$ Ano $2^{\circ}$ Ano $3^{\circ}$ Ano $4^{\circ}$ Ano

\begin{tabular}{lcccc}
\hline Disciplinas do Ensino Médio & & & & \\
\hline Biologia & $\mathrm{X}$ & $\mathrm{X}$ & & \\
Educação Artística & $\mathrm{X}$ & & & \\
Educação Física & $\mathrm{X}$ & $\mathrm{X}$ & $\mathrm{X}$ & $\mathrm{X}$ \\
Física & & $\mathrm{X}$ & $\mathrm{X}$ & \\
Geografia & $\mathrm{X}$ & & & \\
História & $\mathrm{X}$ & $\mathrm{X}$ & & \\
L.E.M. (Inglês) & & & $\mathrm{X}$ & \\
Língua Portuguesa & $\mathrm{X}$ & $\mathrm{X}$ & $\mathrm{X}$ & $\mathrm{X}$ \\
Matemática & $\mathrm{X}$ & $\mathrm{X}$ & $\mathrm{X}$ & \\
Química Geral & $\mathrm{X}$ & $\mathrm{X}$ & & \\
\hline
\end{tabular}

Disciplinas do Curso de Licenciatura e Bacharelado em Química

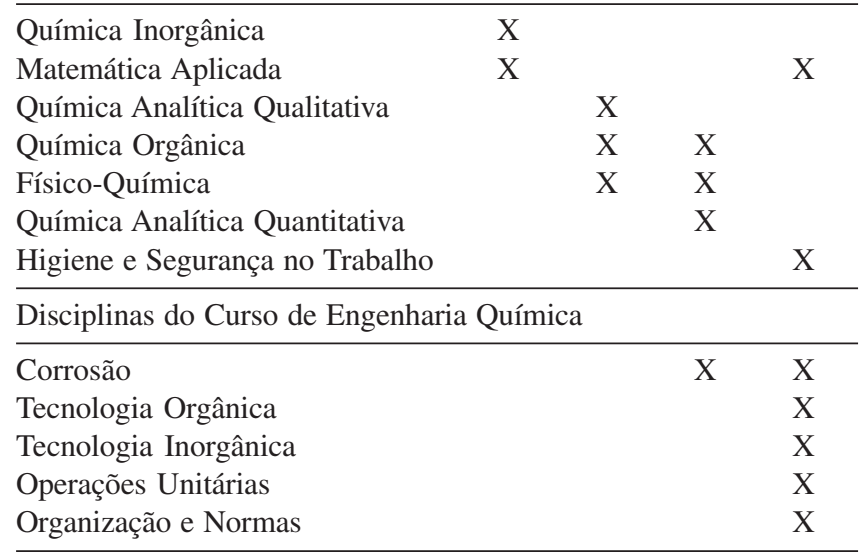

de Engenharia Química, enquanto as demais são encontradas no curso de Licenciatura e Bacharelado em Química. Estas disciplinas eram trabalhadas de modo mais superficial em relação à abordagem realizada no ensino superior, enfatizando os aspectos operacionais de cada uma destas disciplinas.

Através da análise da escola como Aparelho Ideológico de Estado (AIE) e dos objetivos da formação profissional em nível médio é possível entender as razões do ensino técnico em química possuir basicamente o mesmo conjunto de disciplinas encontradas no nível superior, só que com conteúdos trabalhados mais superficialmente em relação aos do nível superior. Segundo a escola como AIE ela deverá legitimar a ideologia da classe dominante, segundo uma sociedade baseada na propriedade individual e na divisão social do trabalho, na qual o fazer destina-se às classes menos favorecidas e o saber às mais abastadas. Assim, o ensino profissional no Brasil origina-se como uma possibilidade de "educar pelo trabalho os órfãos, pobres e desvalidos da sorte, retirando-os das ruas", moralizando e educando a população excluída, através do trabalho, para que eles apresentem comportamentos socialmente mais aceitáveis. Como este grupo de pessoas é destinado a assumir funções apenas operacionais, segundo uma organização produtiva taylorista-fordista, uma formação mais superficial que a formação para funções mais intelectualizadas tornava-se suficiente e também mais barata, portanto, mais adequada às necessidades sociais daquele momento.

O predomínio das aulas teóricas e práticas de Química, na grade anual, era viabilizado através da redução da carga horária total de disciplinas como geografia e história, que passavam a compor a grade anual somente do $1^{\circ}$ ano para geografia e $1^{\circ}$ e $2^{\circ}$ anos para história. A carga horária anual das disciplinas de português e matemática era mantida, em níveis similares em relação à do ensino médio. 
As aulas práticas e as atividades de laboratório eram marcadas pela repetição exaustiva das operações, na qual grande parte das práticas eram realizadas individualmente, inúmeras vezes, até que os resultados fossem reprodutíveis, permitindo o desenvolvimento de habilidades operacionais (fazer).

O desenvolvimento das habilidades operacionais torna-se indispensável quando se tem processos produtivos operados manual, ou visualmente. As aulas práticas eram treinos para realização das atividades em que os meios de produção encontravam-se organizados segundo o modelo taylorista-fordista.

O antigo Ensino Técnico em Química era destinado ao alunado que tivesse concluído o Ensino Fundamental. Após a reforma, passa a ser destinado aos alunos que já tenham concluído o ensino médio e outros cursos técnicos conforme o decreto $\mathrm{n}^{\circ} 2208 / 97$ descrito a seguir sendo, portanto, designado Pós-Médio.

De acordo com o Decreto $n^{\circ} 2208 / 97^{15}$ que regulamenta o Parágrafo do Art. 36 e os Arts. 39 a 42 da Lei no 9394/96 ${ }^{12}$, a educação profissional (da qual o antigo ensino técnico agora faz parte) compreende o nível técnico, que é "destinado a proporcionar habilitação profissional a alunos matriculados ou egressos do ensino médio e técnico" [Art. $3^{\circ}$, inciso II]. Este nível da educação profissional tem organização curricular própria e independente do ensino médio, podendo ser oferecida de forma concomitante ou na sua sequiência [Art. $5^{\circ}$ ]. Os currículos serão estruturados em disciplinas, que podem ser agrupadas sob a forma de módulos [Art. $8^{\circ}$ ].

Há uma minuta de decreto em trâmite que revoga o Decreto $\mathrm{n}^{\circ}$ 2208/97, e regulamenta os Art. 35, 36 e os Art. de 39 a 42 da Lei ${ }^{\circ}$ 9394/96, possibilitando a educação profissional na forma de habilitação técnica ser desenvolvida de forma integrada, concomitante ou seqüencial ao ensino médio. Na forma concomitante poderá ser realizada na mesma instituição, em instituições distintas do mesmo sistema ou não ou em instituições especializadas; os alunos que concluírem o curso técnico, sem a conclusão do ensino médio não farão juz ao diploma de técnico.

O curso de técnico em química estruturado de acordo com a nova legislação como pós-médio é oferecido em módulos, nos quais o aluno matricula-se nas disciplinas que desejar, criando seu próprio currículo, fazendo com que os conhecimentos sejam mais fragmentados que no antigo curso. O conteúdo programático específico da formação química além de manter as oferecidas no técnico anterior, foi ampliado. Algumas disciplinas que antes não faziam parte do programa do curso, como estatística, disciplinas aplicadas à instrumentação e técnicas como espectroscopia na região do UV-Vis (Ultra Violeta e Visível), entre outras, passam a integrar o programa. Contudo, o tempo disponível para trabalhar os conteúdos é menor, pois o curso como um todo tem duração de 2 anos, realizado em módulos de 3 meses de duração, no qual cada módulo corresponde a uma disciplina. $\mathrm{O}$ curso atual tornou-se muito mais superficial, mais rápido e com ênfase na repetição ainda como no curso anterior, mantendo assim características taylorista-fordistas.

Com a reestruturação produtiva surge uma nova forma de gestão segundo o modelo toyotista, baseado na produção flexível e na microeletrônica, resultando em novas necessidades profissionais que não se limitam ao domínio de tarefas exclusivamente operacionais. Como exemplos pode-se citar relacionamento interpessoal, capacidade de trabalho em equipe e domínio de novas técnicas para manuseio de equipamentos com base microeletrônica. Na nova forma de produção segundo o modelo toyotista, os trabalhadores são membros de equipes e cada um torna-se responsável pelo processo como um todo, operando meios de produção robotizados e informatizados.

Assim, a formação profissional deveria proporcionar o desenvolvimento de outras habilidades além das operacionais, já desenvolvidas anteriormente. É esta perspectiva constante no discurso ofi- cial que justifica a reforma do ensino profissional de nível médio, que passa a ser ofertado em nível de pós-médio. A formação profissional do técnico em química, atualmente oferecida em Curitiba, é estruturada em módulos, nos quais cada disciplina tem duração de apenas 3 meses e o conteúdo programático ainda foi ampliado em relação ao anteriormente ofertado, aumentando a fragmentação, e tornando a formação mais aligeirada.

$\mathrm{O}$ fato de a escola não estar atendendo às necessidades reais dos trabalhadores não se constitui algo inesperado, pois sendo a escola parte de um sistema de mediações deverá manter as relações de hegemonia já existentes em uma sociedade organizada com base na propriedade individual. $\mathrm{O}$ fato intrigante é que a formação profissional encontra-se inadequada também sob o ponto de vista do mercado e do sistema capitalista.

A escola deverá abranger o conhecimento básico de química de forma sólida, possibilitando que este profissional possa se adequar às diferentes situações. Um conhecimento fundamentado em química poderá facilitar a incorporação dos diferentes processos químicos e a adaptação desses profissionais aos diferentes meios de produção que poderão encontrar no mundo do trabalho.

A escola poderá estar oferecendo, além de uma base sólida em química aos futuros trabalhadores, uma formação direcionada aos aspectos da atuação profissional, como o conhecimento de seus direitos e deveres, as condições de trabalho e o piso salarial. A abordagem dessas informações pode servir para alertar estes profissionais durante sua formação e favorecer condições para que possam se organizar enquanto classe profissional, possibilitando ações que visem o rompimento do processo de deterioração das suas condições profissionais.

O ensino profissional pós-médio vem se apresentando como uma alternativa rápida e fácil de profissionalização, comparando-se com a profissionalização do ensino superior. No entanto a redução de tempo, em relação à versão anterior, juntamente com o aumento de conteúdos levam a uma formação mais precarizada do que o antigo ensino técnico simultâneo ao ensino médio apresentava, contrariando a proposta de desenvolvimento de profissionais intelectualmente autônomos e criativos.

Portanto, a reforma da educação profissional, mesmo resolvendo o problema do aumento de titulação das pessoas, tanto para o Estado como também para as empresas a curto prazo, não resolve o problema do ponto de vista do trabalhador e da empresa a médio e a longo prazos, os quais, além da titulação também necessitam de conhecimentos, e de autonomia, necessários ao desempenho de suas funções cotidianas.

Na pesquisa realizada no Brasil sobre indústrias do setor de química fina de capital nacional, Mercado Suarez aponta como obstáculos ao desenvolvimento dessas indústrias três fatores principais: a falta de qualificação de pessoal, a capacidade gerencial e a questão de mercado; sendo que o principal obstáculo é em relação à inadequação da formação dos profissionais ${ }^{16}$.

$\mathrm{O}$ mercado de trabalho exige do profissional um acréscimo de conhecimento, principalmente qualitativo e não somente quantitativo. Se o profissional desejar manter sua empregabilidade, ele deverá por si "correr atrás do prejuízo", responsabilizando-se solitariamente pela sua formação com qualidade.

Durante a pesquisa de campo realizada nas empresas em que os profissionais técnicos em química atuam, surgiu um fato que ilustra a afirmação anterior na fala de um profissional químico (de nível superior), supervisor do laboratório da empresa $\mathrm{H}$, uma empresa de renome na área química e já reestruturada:

"Aqui nós estamos trocando um técnico em química que está sendo dispensado, pela contratação de um Químico, 
de formação superior, pois alguns técnicos não tem atendido às necessidades da empresa."

A maioria das empresas, na tentativa de amenizar os problemas referentes a formação e à conduta profissional, tem oferecido cursos periódicos e rápidos de treinamento a seus funcionários. Os treinamentos mais comuns são os destinados a melhoria do relacionamento interpessoal, seguidos de cursos específicos como primeiro socorros, produtos químicos, metrologia, entre outros.

Portanto, enquanto as atribuições do trabalhador no mercado de trabalho são crescentes, a formação está ficando cada vez mais precarizada, dificultando ainda mais a manutenção do emprego pelos profissionais, que cada vez recebem "menos" durante a formação profissional e são mais exigidos no ambiente de trabalho, o que requer um saber em contínua expansão.

O Estado não consegue dar conta de atender a demanda de formação profissional de forma adequada, devido à ausência de investimentos; no entanto, prevendo que não haverá pleno emprego para todos, não se preocupa com esta formação, deixando que o mercado se encarregue de selecionar os profissionais. Os trabalhadores, por sua vez, procuram por conta própria melhorar sua formação no intuito de se manterem empregados.

\section{ESTUDO DE CAMPO}

O trabalho foi desenvolvido a partir do materialismo histórico dialético, teoria e método desenvolvido por Karl Marx e Friedrich Engels ${ }^{17}$. Considera-se, a partir dessa base epistemológica, que o que os indivíduos são, depende de como produzem seus meios de vida e do que produzem; deste modo, os indivíduos são dependentes das condições materiais de sua produção. $\mathrm{O}$ trabalho é a materialização concreta do que os indivíduos produzem e de como produzem seus meios de vida. Portanto, a abordagem a partir do trabalho e do trabalhador constitue meio importante para a interpretação da realidade que nos cerca, já que estamos partindo da vida material concreta ${ }^{18}$.

Consideramos que a atividade profissional se concretiza como práxis humana, e realizamos a caracterização do profissional do ponto de vista do trabalhador. A categoria práxis é central para Marx, na medida em que só a partir dela tem sentido a atividade do homem, sua história, assim como o conhecimento.

A práxis refere-se em geral, à ação, à atividade livre, universal, criativa e auto criativa, por meio da qual o homem cria e transforma seu mundo humano e histórico e a si mesmo. A práxis é resultado da unidade do pensamento e da ação, portanto a unidade entre teoria e prática. $\mathrm{O}$ resultado da articulação entre teoria e prática culminada na práxis possibilita a transformação e até a revolução ${ }^{19}$.

As estratégias metodológicas adotadas para caracterizar a formação profissional do técnico em química foram o levantamento bibliográfico, as visitas à escola técnica, a aplicação de Questionários de Pesquisa e a análise dos currículos do ensino técnico e do ensino superior do curso de Química.

A escola técnica visitada foi o Centro Estadual de Educação Profissional de Curitiba (CEEP) que é, atualmente, o único responsável pela formação profissional técnica de nível médio da área de química em Curitiba. O currículo de nível superior utilizado para comparação foi o do curso de Licenciatura e Bacharelado em Química da Universidade Federal do Paraná.

Estruturou-se um questionário, que foi aplicado em sala de aula, para uma turma do período diurno (23 alunos) e seis turmas do período noturno (91 alunos) da escola, durante os meses de novembro e dezembro de 2001.

$\mathrm{Na}$ etapa seguinte do trabalho foi realizada a caracterização dos profissionais da área de química de nível médio já inseridos no mer- cado de trabalho a partir da investigação da atuação desses profissionais, verificando que atividades eles exerciam, quais as perspectivas de ascensão na carreira e quais as formas de atualização e desenvolvimento profissional de que dispõem como trabalhadores, contribuindo, assim, com novos conhecimentos sobre o campo do técnico químico. Estruturou-se um roteiro de entrevista que, sendo mais flexível que o questionário, mostrou-se mais adequado à diversidade de situações apresentadas pelos profissionais. As entrevistas ocorreram no local de trabalho em horário de expediente e nas trocas de turno, para alguns casos.

Os resultados foram obtidos através de entrevistas com 27 trabalhadores da área de química em nível médio, em 8 empresas diferentes. Foram entrevistados 5 profissionais de uma empresa estatal de tratamento de água e esgoto (A), 7 profissionais de indústria multinacional de refrigerantes $(\mathrm{B}) ; 1$ profissional de indústria multinacional italiana de detergentes e produtos enólogos (C); 1 de indústria de inseticidas domo-sanitários (D). Inseticidas domo sanitários referem-se aos de uso doméstico, como inseticidas para formigas, ratos, baratas, moscas, etc.; 1 profissional que se aposentou em 2001 em uma indústria de adesivos e agora presta serviços a uma outra indústria regional de resinas e adesivos (E) e o sócio fundador dessa última indústria de resinas e adesivos (E). Foram também entrevistados 4 profissionais de indústria multinacional dinamarquesa destinada à produção de enzimas de aplicação industriais variadas (F); 6 profissionais de indústria multinacional americana destinada à produção de tintas automotivas (G) e 1 profissional de indústria propriamente química, que é uma multinacional destinada à produção de peróxido de hidrogênio $100 \%(\mathrm{H})$. As informações a respeito das empresas pesquisadas encontram-se expostas na Tabela 2.

\section{RESULTADOS E DISCUSSÃO}

A partir da análise dos questionários dos alunos que estavam cursando o pós-médio em química, foi possível identificar algumas características a respeito da origem, das perspectivas e do interesse desses alunos em relação à escolha do curso e outros aspectos sociais, que permitiram traçar o perfil desses alunos trabalhadores e, principalmente, identificar quais e quantos são os profissionais já atuantes na área de química que se encontram em formação atualmente.

Do total dos 91 alunos do noturno entrevistados, 49 são trabalhadores atuando na área de química ou áreas correlatas. Destes 49 alunos trabalhadores 4 já se encontram atuando como técnicos em química, 18 estagiando e 27 atuando em áreas correlatas à química, ou seja, não como técnico em química propriamente dito mas em ocupações em que o conhecimento químico se encontra presente. Foram detectadas ocupações como auxiliar de laboratório, laboratorista, controle de qualidade, operador de refinaria, vendedor de equipamentos e produtos químicos, entre outras.

A escola não tinha lançado no mercado de trabalho, até o momento da realização da pesquisa, os egressos do curso de técnico em química em regime de pós-médio, pois a primeira turma concluiu o curso no início de 2002. Contudo grande parte desses alunos, 53,85\% dos entrevistados, já são trabalhadores atuando na área de química ou em áreas correlatas.

Do total de alunos entrevistados, $32 \%$ apontam o fato de já atuarem na área e as perspectivas da área como sendo fatores responsáveis pela escolha do curso. Dos que já atuam na área, 24\% buscam na certificação maiores condições de manter a empregabilidade e cerca de $8 \%$ identificam como perspectivas da área maiores chances de conquistar a empregabilidade. Estes dados estão representados na Figura 1.

Foi possível identificar que os alunos procuram o curso de pósmédio em Química principalmente pelo gosto à química e pela 
Tabela 2. Informações sobre as empresas pesquisadas

\begin{tabular}{llll}
\hline Empresa & Tipo & Setor & Características \\
\hline A- Tratamento de água e saneamento & Estatal & Serviço & \\
\hline $\begin{array}{l}\text { B- Produção de bebidas não alcoólicas } \\
\text { gaseificadas }\end{array}$ & Multinacional & Industrial & $\begin{array}{l}\text { 700 funcionários, produção: 204.000 m³/ano } \\
\text { atuação de mercado: PR e interior de SP }\end{array}$ \\
\hline $\begin{array}{l}\text { C- Produção de detergentes especiais industriais } \\
\text { e produtos enólicos, matérias-primas para vinhos } \\
\text { e terras filtrantes como condjo unidade única no Brasil }\end{array}$ & $\begin{array}{l}\text { Multinacional } \\
\text { italiana }\end{array}$ & Industrial & $\begin{array}{l}\text { 20 funcionários, sendo o mercado nacional } \\
\text { atendendo somente o mantes na indústria }\end{array}$
\end{tabular}
e terras filtrantes como coadjuvantes na indústria cervejeira

D- Produção de inseticidas domo-sanitários

Nacional Familiar Industrial

35 funcionários, atuando no mercado da região sul e sudeste do país, com uma produção mensal de 10000 caixas de produtos variados

E- Produção de adesivos para a indústria moveleira, Nacional Industrial 24 funcionários atuando no mercado interno, civil e papeleira. Os produtos principais são resinas uréia-formol e fenol-formol

\begin{tabular}{|c|c|c|c|}
\hline F- Produção de enzimas industriais & $\begin{array}{l}\text { Multinacional } \\
\text { dinamarquesa }\end{array}$ & Industrial & $\begin{array}{l}160 \text { funcionários, produção de } 200 \text { t/mês } \\
\text { atuação de mercado: Brasil e América Latina }\end{array}$ \\
\hline $\begin{array}{l}\text { G- Produção de tintas automotivas. } \\
\text { Esta unidade somente realiza a diluição e a } \\
\text { adequação das tintas produzidas na matriz } \\
\text { brasileira em Sumaré }\end{array}$ & $\begin{array}{l}\text { Multinacional } \\
\text { americana }\end{array}$ & Industrial & $\begin{array}{l}29 \text { funcionários, sendo } 12 \text { contratados } \\
\text { e } 17 \text { de uma outra empresa tercerizada. } \\
\text { Produção de } 270 \text { carrocerias/dia, atuação de } \\
\text { mercado: todas as montadoras de carros do } \\
\text { Brasil, exceto uma }\end{array}$ \\
\hline $\begin{array}{l}\text { H- Empresa destinada à produção de peróxido de } \\
\text { hidrogênio } 100 \%\end{array}$ & Multinacional & Industrial & $\begin{array}{l}80 \text { funcionários, produção média anual de } \\
75 \mathrm{t} \text { de } \mathrm{H}_{2} \mathrm{O}_{2} 100 \%\end{array}$ \\
\hline
\end{tabular}

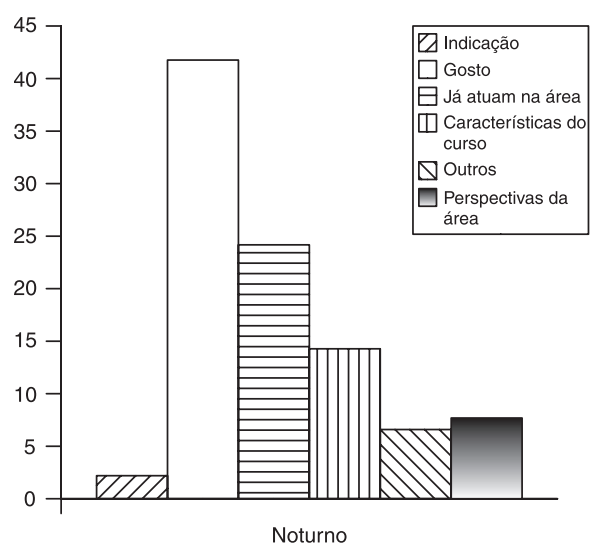

Figura 1. Razões da escolha do pós médio em Química

potencialidade da área, presente em várias fases de muitos processos produtivos, que acreditam favorecer a empregabilidade.

Este interesse por parte dos alunos trabalhadores em relação à química e a percepção da sua importância como um conhecimento diferenciador na busca constante por melhor condição de disputar vaga no mercado de trabalho vêm reforçar ainda mais a importância do conhecimento químico nas sociedades atuais e, desta forma, também alertar para a criação de mecanismos que possibilitem uma melhor divulgação e disseminação da ciência Química.

Os alunos entrevistados encontram-se na maior parte na faixa etária de 18 a 23 anos, com renda familiar de até 7 salários mínimos, tanto para o diurno como para o noturno, e são oriundos de famílias cuja maioria dos pais possui escolaridade de ensino fundamental completo (noturno) e de ensino médio completo para os dos diurno.

Segundo os dados levantados, é possível identificar as diferenças entre as famílias dos alunos que procuram o curso Técnico quí- mico noturno e diurno. O que diferencia estas famílias é a escolaridade dos pais. Os alunos que se encontram cursando o técnico em química no período diurno são oriundos de famílias em que os pais possuem, em média, o ensino médio completo e os alunos do noturno, de pais com apenas o ensino fundamental completo. Apesar das famílias dos alunos tanto do diurno como do noturno possuírem em média a mesma renda familiar mensal, o número de anos de permanência na escola é diferenciado, evidenciando que os alunos do noturno são de maior mobilidade social que os do diurno. A inexistência de diferença na renda familiar deve-se ao fato de que os alunos do noturno, por serem trabalhadores, contribuem para o acréscimo da renda dos pais, obtendo assim a mesma renda familiar encontrada nas famílias dos alunos do diurno.

Para as turmas do noturno, a maioria dos alunos já são trabalhadores que se encontram atuando em áreas correlatas à química, e nas mais diversas áreas para as do diurno. A maioria está no setor industrial, já desempenha a função há mais de 4 anos e possue registro em carteira profissional. Dentre os entrevistados, $8 \%$ têm mais de 30 anos e são profissionais atuando na área química em busca de atualização/aperfeiçoamento como forma de requalificação. Os alunos do último período estão mais envolvidos em estágio, portanto, sem vínculo empregatício.

Grande parte destes alunos é oriunda de escolas públicas, sendo $82 \%$ do total de alunos do noturno, $51 \%$ desses alunos concluíram o ensino médio entre os anos de 1999 e 2000, manifestando um grande interesse no prosseguimento de estudos em nível superior, logo após a conclusão do curso de pós-médio.

Analisando os resultados obtidos através das entrevistas com os profissionais técnicos químicos contatados diretamente junto às empresas, tem-se que dos 27 profissionais entrevistados, $12(44,4 \%)$ são do sexo feminino e $15(55,5 \%)$ do sexo masculino.

A maioria dos entrevistados declara não possuir participação social, seja em clubes sociais ou freqüência em ações comunitárias. 
Apenas 9 dos entrevistados participam na comunidade, através de grupos religiosos. As atividades mais citadas como atividades de lazer são assistir TV, leituras diversas, apenas 6 praticam um esporte como futebol ou vôlei, sendo que a prática de esportes não é realizada com periodicidade regular. Das atividades recreativas realizadas por algumas empresas, 5 entrevistados não participam, 2 participam diariamente, 1 participa 1 vez na semana, 1 participa mensalmente e 1 que quase não participa (Figuras 2 e 3 ).

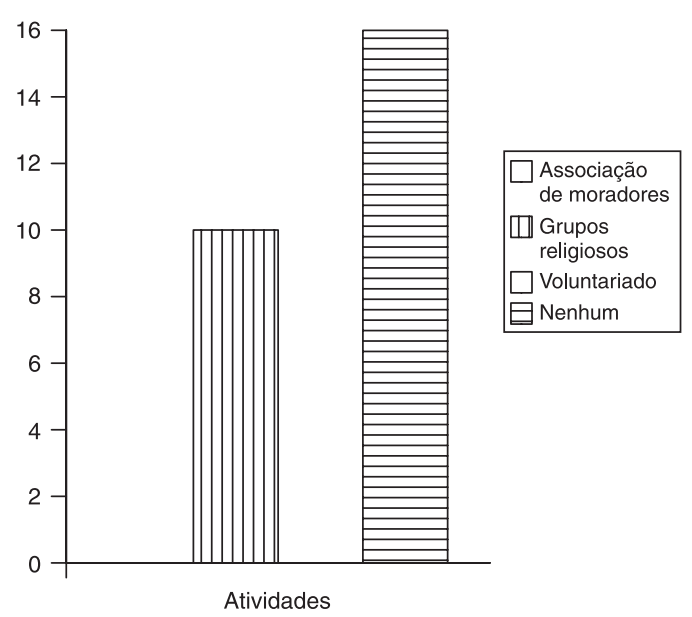

Figura 2. Freqüência de participação na comunidade

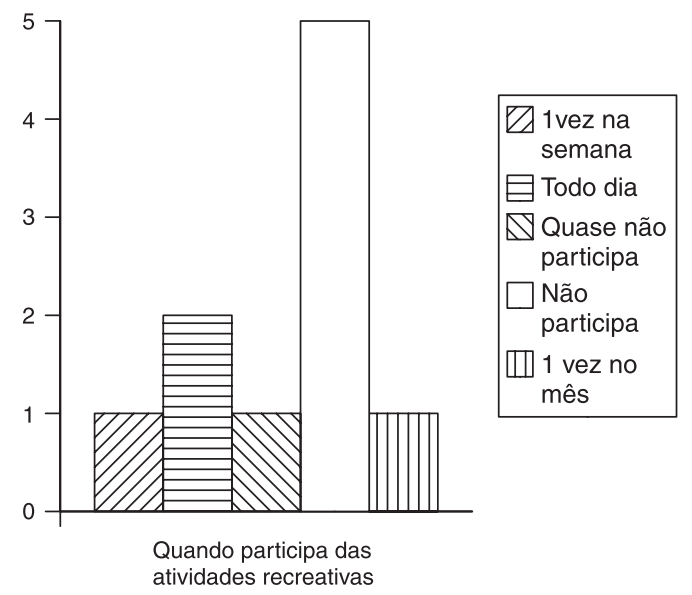

Figura 3. Freqüência de participação em atividades recreativas

Os profissionais relatam a ausência de disponibilidade de tempo para a realização de outras atividades, pois trabalham o dia todo e, muitas vezes, à noite realizam cursos relacionados às exigências do trabalho. Durante os finais de semana estão muito cansados para sair ou realizar atividades culturais, de lazer e recreação.

Dentre os profissionais entrevistados em relação à faixa etária, 10 encontram-se entre 20 a 25 anos, 3 de 26 a 28 anos, 8 entre 35 a 40 anos e 3 com mais de 40 anos. Grande parte (23) destes profissionais é oriunda de escolas públicas, sendo que desses, 2 concluíram o ensino médio supletivo e estão cursando atualmente o pós-médio técnico em química. A maioria já possui formação técnica em química (17), muitos estão cursando o pós-médio técnico em química (6), 3 são técnicos de alimentos e somente 1 é técnico em saneamento. A maioria (15) não recebeu treinamento inicial para assumir a função que desempenha.

Grande parte das empresas (6) oferecem cursos periódicos de treinamento, sendo o mais comum o de relacionamento interpessoal, seguido de cursos específicos como primeiro socorros, produtos químicos, metrologia, entre outros.

Os profissionais sugerem que, segundo as novas exigências profissionais, a escola de formação técnica poderia oferecer cursos de implementação de ISO, de procedimentos, curso de informática, realizar maior número de visitas em empresas para demonstração do processo industrial e aumentar as aulas práticas direcionadas a alguns processos produtivos mais comuns.

Quanto à formação profissional, os trabalhadores que ainda não possuem formação técnica em química estão atualmente cursando no período noturno. Deste modo, a qualificação do trabalhador tem ficado sob total responsabilidade do próprio trabalhador, como mecanismo de manter a empregabilidade, seja pela obtenção do título formal ou seja pela fundamentação teórica necessária para o acompanhamento da novas tecnologias, ou por ambas. Assim a qualificação profissional, a empregabilidade e a manutenção do emprego tornam-se responsabilidades exclusivas dos próprios trabalhadores.

Os profissionais que se encontram realizando a formação profissional atualmente buscam na formação, em primeiro lugar, a certificação como requisito formal, já que as empresas necessitam de pessoal qualificado para conquistar também suas certificações de qualidade. Em segundo lugar, o conhecimento como fundamentação teórica para as novas tecnologias, já que ele deverá saber utilizar os novos equipamentos, deverá ter noções de manutenção e reparo, bem como interpretar as informações obtidas através da utilização destes novos equipamentos. Esse fator poderá ser ilustrado com alguns relatos, a seguir:

"A diferença entre quem tem o curso técnico e quem não tem: é quem tem o curso técnico consegue interpretar o que acontece e porque está acontecendo; quem não tem o curso segue somente as instruções." Técnico $n^{\circ} 1$, de 26 anos, da empresa G: produção de tintas automotivas.

"Antes as análises eram feitas sem saber o porquê, é mais gratificante fazer uma coisa que você sabe porquê." Técnico $n^{\circ} 7$, de 46 anos, da empresa B: produção de refrigerantes

A formação profissional e a formação continuada passam a ser responsabilidade exclusiva do próprio trabalhador. Desta forma, ele terá que arcar com todas as responsabilidades de sua qualificação, inclusive com as despesas e com a disponibilidade de horário para a realização desta que, geralmente, ocorre em contra turno. Deste modo, o próprio trabalhador tem tomado a iniciativa de procurar a melhoria na sua formação, na tentativa de manter sua empregabilidade.

A formação mais aligeirada e fragmentada leva a uma formação que precariza e descaracteriza a atuação profissional do técnico em química, já que este profissional não terá condições de atuar no mercado de trabalho que cada vez está mais exigente quanto à performance dos trabalhadores. Esta situação poderá levar à precarização e descaracterização dos demais profissionais da área como os químicos que, na seqüência, poderão estar assumindo responsabilidades anteriormente destinadas aos técnicos de nível médio.

A grande maioria (20) dos profissionais entrevistados não são a única fonte da renda familiar e possuem uma renda mensal que varia de 3 a 7 salários mínimos. Eles apresentam uma grande variação de remuneração e de denominação profissional pela qual são contratados, apesar de estarem atuando na mesma empresa, realizando as mesmas funções. Estas características dificultam a fiscalização, por parte dos sindicatos, do cumprimento das legislações.

A legislação segundo a Lei $4950 \mathrm{~A} / 66^{20,21}$ estabelece um piso salarial para os profissionais de nível superior, mas não faz referên- 
cia ao nível técnico. Os sindicatos de cada região sugerem o piso que deverá ser praticado pelos contratantes. Desta forma, há uma variação no salário mínimo da categoria, pois cada região estipula um valor.

Foram contatados os Sindicatos dos Químicos dos Estados do Paraná, de São Paulo e do Rio Grande do Sul, no intuito de obter informações a respeito do piso salarial praticado em cada região. $\mathrm{O}$ sindicato de maior dificuldade de acesso foi do Estado do Paraná pois não possui site na internet e não há disponibilidade do número telefônico.

O sindicato do Estado de São Paulo ${ }^{21}$, através de acordos com as empresas, recomenda um valor que fica em aproximadamente um terço ( $\mathrm{R} \$ 551,00$ por $8 \mathrm{~h}$ ) do piso salarial dos profissionais de nível superior, que é de 6 salários mínimos para $6 \mathrm{~h}$. O parecer do sindicato dos químicos do Rio Grande do $\mathrm{Sul}^{20}$ é de que o técnico deva ter uma remuneração de 3 salários mínimos por 6 h diárias trabalhadas, ou seja, equivalente à metade do salário de nível superior. $\mathrm{O}$ sindicato dos químicos do Estado do Paraná atualmente recomenda um salário base mínimo, acordado entre as empresas e o sindicato, no valor de $\mathrm{R} \$ 426,17$ para jornada de $8 \mathrm{~h}$.

A maior dificuldade na obtenção das informações junto à organização sindical do Estado do Paraná e o menor piso salarial refletem que a atuação sindical nesse é ainda muito inicial, o que pode contribuir para a presença da categoria multi tarefas na vida profissional dos técnicos químicos.

Observou-se diferenças regionais entre os salários dos técnicos em química, não havendo uma normatização nacional. Os trabalhadores são submetidos a acordos regionais estabelecidos entre os sindicatos e as empresas, sem qualquer orientação que possa conduzir às discussões do valor do piso salarial mínimo unificado da categoria.

A participação e atuação sindical desses trabalhadores é mínima, pois verificou-se que apenas 3 profissionais participam de reuniões sindicais, não havendo nenhuma regularidade nessa frequiência.

Dos entrevistados, 14 não possuem registro no Conselho Regional de Química (CRQ); a metade destes entrevistados coincide (7) com aqueles profissionais que estão atualmente cursando o pós-médio técnico em química, e portanto ainda não possuem habilitação para se cadastrar junto ao CRQ. A outra metade já são trabalhadores formados atuando sem registro no CRQ.

Dentre os profissionais entrevistados, 15 já tiveram empregos anteriores na área de química e 14 já desempenham a função há mais de 5 anos, e todos possuem registro em carteira profissional. Eles apontam os anos de experiência na área como um fator favorável para competir no mercado de trabalho e, como um dos obstáculos, a idade mais avançada. Isto se concretiza através do início precoce no mundo do trabalho. O jovem irá buscar no primeiro emprego a experiência, a fim de aumentar a competitividade como trabalhador.

Os impactos da globalização são percebidos pelos profissionais como necessidade de maior domínio de conhecimentos e de titulação; os entrevistados apontam os anos de experiência na área como um fator favorável para competir no mercado de trabalho, e como principais obstáculos, a falta de conhecimento de um outro idioma, a falta do curso superior e a idade avançada.

"Antes era necessário saber o máximo do mínimo, agora saber o mínimo do máximo que você puder-polivalênciainterdisciplinariedade e liderança." Técnico $\mathrm{n}^{\circ} 2$, de 24 anos, da empresa G: produção de tintas automotivas.

Observou-se que as funções que estes profissionais desempenham são as mais variadas possíveis, não havendo um padrão predeterminado; essas funções diferem entre si em virtude do tipo e do tamanho da empresa e da relação produtiva que cada um desses trabalhadores têm com a empresa. Estes fatores observados apontam para uma desprofissionalização do técnico em química visto que estes, mesmo sendo técnicos em química, não têm atividades de rotina em comum.

O que todos estes trabalhadores têm em comum é o domínio do conhecimento químico, o que os diferencia dos demais. Isto talvez explique o fato de estarem acumulando cada vez mais funções, antes delegadas a outros. Mas as funções referentes ao conhecimento químico não são facilmente delegadas a qualquer outro profissional. Assim por exemplo, o técnico $\mathrm{n}^{\mathrm{o}} 3$, de 38 anos, da empresa B tem acumulado a função de controle de estoque, anteriormente realizada por outros funcionários da empresa.

Os efeitos da reestruturação podem ser retratados pelos relatos destes profissionais em relação ao número de funções e de atividades que desempenham no cargo que ocupam na empresa, que vêm aumentando nos últimos anos.

"Houve reestruturação para realização de atividades mais rápidas e eficientes, para diminuição de pessoal aumentando a rotina e o volume de serviço, pois sempre há novos equipamentos." Técnico $n^{\circ} 1$, de 35 anos, da empresa H: produção de peróxido de hidrogênio.

\begin{abstract}
"Muita organização, diminui o número de pessoas em algumas funções, aumento gradativo de funções." Técni$\operatorname{co~}^{\circ}{ }^{2}$, de 36 anos, da empresa A: tratamento de água e esgoto

"Há a preocupação com custo, desperdícios, até de pessoal que gerou toda uma nova cultura. Há mais tecnologia: equipamentos que necessitavam de 3 ou 4 pessoas para operar hoje necessitam de 1 só." Técnico n ${ }^{\circ} 3$, da empresa B: produção de refrigerantes
\end{abstract}

Segundo estes relatos é possível identificar que está ocorrendo uma intensificação do trabalho do técnico em química. Eles acreditam que o trabalho ficou mais fácil, mas ao mesmo tempo, maior. Em relação à maior facilidade atribuída ao trabalho, ao mesmo tempo em que aumentam as funções e as responsabilidades, pode-se interpretar que está ocorrendo um esforço mental maior em relação ao esforço físico anteriormente necessário no desempenho das tarefas realizadas por estes profissionais.

Observou-se também que, além do aumento do número de funções realizadas, há um aumento na complexidade das funções, em conseqüência do emprego de novas tecnologias instrumentais. As falas a seguir exemplificam bem isto.

"Era mais simples, as análises agora são mais criteriosas, equipamentos mais modernos facilitam o trabalho, aumentou a freqüência da análises e houve um aumento de funções.” Técnico $\mathrm{n}^{\circ} 7$, de 46 anos, da empresa B: produção de refrigerantes

"O pessoal está mais qualificado - modernização de equipamentos, informatização - facilitam o trabalho." Técnico $\mathrm{n}^{\circ}$ 2, da empresa B: produção de refrigerantes

"É exigido bem mais do indivíduo, tem mais oportunidades porém é muito desgastante. A globalização é preocupante dá falsa aparência de melhoria." Técnico $n^{\circ} 1$, da empresa C: produção de detergentes industriais e produtos enólicos.

A maioria dos entrevistados (22) relata que a empresa em que 
trabalham é aberta ao recebimento de opiniões, críticas e sugestões provenientes dos funcionários, informações na maioria das vezes coletadas através de reuniões e que há um grande incentivo moral, motivacional, para aumentar a participação. Houve somente um caso em que o incentivo era participação nos lucros, no caso da empresa $\mathrm{H}$, que se destina à produção de peróxido de hidrogênio $100 \%$. As empresas coletam informações dos trabalhadores no intuito de aproveitar o conhecimento tácito dos técnicos e, assim, possibilitar a incorporação de melhorias no processo de produção.

Os profissionais na maioria (23) posicionaram-se favoráveis à existência de uma carreira na empresa. A maioria aponta a carreira como ponto positivo por gerar motivação pessoal, pelo reconhecimento de seu trabalho, além de outros fatores, como a conquista de melhoria salarial, de maior segurança e de maiores perspectivas profissionais. No entanto, o que se observa é que não há possibilidade de seguir carreira na área de química, pois não há carreira, exceto nas empresas estatais, que promovem ascensão por meio de concursos, que são esporádicos e imprevisíveis.

Na busca de informações a respeito da profissão do técnico em Química junto ao Ministério do Trabalho, encontrou-se a Classificação Brasileira das Ocupações ${ }^{5}$ (CBO). A CBO é construída através da coleta de informações realizadas diretamente com os trabalhadores no local de trabalho, sendo assim, estas diferenças observadas, descritas anteriormente, entre as atribuições previstas pela $\mathrm{CBO}$ e aquelas observadas durante a pesquisa de campo caracterizam e confirmam o quanto os técnicos em química têm acumulado funções.

Na descrição de algumas atribuições do técnico em química segundo a CBO, é possível identificar pontos nos quais há uma ênfase privilegiando os conhecimentos operacionais, mostrando que a profissão do técnico em química ainda se encontra muito ligada ao modelo de produção taylorista-fordista. Esta ênfase presente nas atribuições do técnico em química dos conhecimentos operacionais, segundo a CBO, pode estar ligada ao fato de que o processo de reestruturação produtiva está em transição, havendo portanto a co-existência do modelo de produção anterior e dos mais atuais, sugerindo que o setor de química não está totalmente reestruturado, mesmo porque a reestruturação do setor de química implica em investimentos de grande porte, o que ocorre normalmente em empresas de tecnologia de ponta.

Na descrição da profissão do técnico em química, segundo a CBO, é possível identificar evidências de que não há uma distinção muito clara do nível de atuação dos diferentes profissionais da área de química. Observou-se isto também na pesquisa de campo, evidenciando uma tendência à desprofissionalização dos trabalhadores da área de química, principalmente em relação ao técnico em química.

A CBO, na descrição resumida das atribuições do profissional técnico em química, apresenta uma expressão que sugere uma certa flexibilização da profissão quando cita “..., fazendo cálculos, elaborando programas e previsões e executando tarefas afins,...”. Pode ser aí incluída qualquer outra responsabilidade e atribuição desta ocupação.

Esta possibilidade de tornar o trabalhador em um executor multitarefas pode fazer com que a profissão se descaracterize, não sabendo o trabalhador qual é realmente sua profissão, dificultando a organização desses trabalhadores em classe, já que não se sabe quem é de qual classe profissional. Isto gera consequiências graves no que diz respeito às mobilizações sindicais e a organização da classe trabalhadora para lutar por melhores salários, condições de trabalho, e a construção de sua carreira, que é percebida como importante pelo trabalhador mas inexistente na maioria dos ambientes pesquisados.

A presença de funções variadas pode dificultar o reconhecimento do trabalhador como pertencente a uma classe profissional, o que pode contribuir para sua descaracterização profissional, podendo gerar um ciclo de desprofissionalização. Ele terá mais dificuldade em iden- tificar em qual sindicato ou conselho deverá se cadastrar; conseqüentemente, este profissional estará se excluindo dos movimentos e organizações trabalhistas responsáveis pela representação dos interesses de sua classe. Como exemplo citamos o caso das empresas A, B e F (ver Tabela 2), que possuem técnicos em química, técnicos em saneamento e técnicos em alimentos realizando basicamente as mesmas funções. O profissional poderá se sentir confuso e assim não saberá em qual sindicato se associar: ao dos técnicos em alimentos, ou ao dos de saneamento, ou ao dos de química. Aqui a categoria multitarefas encontra-se relacionada com uma outra categoria que é a desprofissionalização, categoria presente inclusive na $\mathrm{CBO}$, conforme citado anteriormente. A utilização desta descrição do Cadastro Brasileiro de Ocupações pelo Ministério do Trabalho só vem dar respaldo à desprofissionalização do técnico em química, que se tornou um executor multi-tarefas.

A presença de multi-tarefas na vida profissional dos técnicos químicos é vista, por alguns desses trabalhadores, como ponto positivo, pois sentem-se mais valorizados e o trabalho passa a ser um pouco menos alienante.

\begin{abstract}
"Há responsabilidade mútua, o grupo é responsável por toda a companhia, mais responsabilidades é bom pois se aprende muito com isso. As especificações dos produtos são alteradas de acordo com as necessidades mundiais podendo mudar a 'cada 10 min' on-line ou conforme as necessidades.” Técnico $\mathrm{n}^{\circ} 1$, da empresa F: produção de enzimas industriais
\end{abstract}

"Mais seriedade, e aumento das responsabilidades; antes era tudo desorganizado, agora melhorou." Técnico $n^{\circ} 4$, da empresa A: tratamento de água e esgoto

O profissional técnico em química, assim como possivelmente outros trabalhadores, encontra-se profissionalmente descaracterizado, em virtude da sobrecarga de funções e responsabilidades, e da não existência de possibilidade de seguir carreira, evidências da precarização que leva à desprofissionalização e às dificuldades crescentes na construção de sua carreira e manutenção de identidade profissional.

A inadequação profissional do técnico em química às necessidades do mercado de trabalho poderá levar à não contratação desses profissionais; como o trabalho não deixará de existir simplesmente pela ausência de profissionais adequados, alguém deverá estar assumindo as atribuições desses profissionais. Portanto, torna-se indispensável oferecer uma formação profissional de qualidade com maior atenção na formação dos professores responsáveis pela formação dos profissionais de nível médio e, conseqüentemente, dos professores de nível superior responsáveis pela formação dos professores que atuarão no nível médio.

A substituição dos técnicos em química por outros profissionais da área poderia estar acontecendo de várias maneiras: profissionais de outras áreas, como técnicos em alimentos e saneamento, estariam assumindo as funções do técnico químico de nível médio e os químicos de nível superior, assumindo as funções do técnico em química. Assim, o químico estaria submetido à sobrecarga e precarização das condições de trabalho ao acumular as duas funções, ou limitar-se a atuar como profissional de nível médio, submetendo-se às limitações de atuação e remuneração.

A classe trabalhadora da área de química, como um todo, acabará sentindo os impactos da desprofissionalização de um dos seus membros; a organização dos profissionais da área de química enquanto classe profissional possibilitaria criar condições de reivindicar melhores condições de trabalho e de formação profissional. 


\section{CONCLUSÃO}

O mercado de trabalho reestruturado, ou seja, na produção organizada segundo o sistema de gestão toyotista, na qual a presença da robotização e da microeletrônica permitem o aumento da produção com um menor número de postos, o trabalho é caracterizado como sendo desenvolvido de forma completa e flexível. Assim, do ponto de vista da produção há exigência de trabalhadores com maior autonomia, com domínio do conhecimento científico, capazes de atuar criativamente e que irão ocupar os restritos postos de trabalho. Por outro lado, a investigação da atuação dos trabalhadores no ambiente de trabalho do técnico químico mostra uma precarização profissional generalizada, envolvendo desde a formação inadequada, o acúmulo de funções, o caráter multi-tarefas, a ausência de planos de carreira, a ausência de sindicalização, até a responsabilização solitária pela sua empregabilidade.

Esta descrição é coerente e intrínseca ao processo de reestruturação produtiva, na qual a exploração é ampliada tanto pela necessidade de um desempenho intelectual maior, decorrente de tarefas mais complexas, como pelo acúmulo de funções provenientes da diminuição dos postos de trabalho. Porém, a presença dessas características pode resultar na desprofissionalização dos trabalhadores já que, estes, sobrecarregados e desamparados, não conseguiriam manter a atualização profissional com a qualidade requerida.

O Estado utilizando a produção como eixo orientador para a promoção de políticas públicas, deixa de lado a visão do trabalhador. A reforma do ensino profissional é centrada na falsa idéia da universalização da formação de qualidade para o trabalhador, propagando o desenvolvimento de habilidades cognitivas superiores e da competência profissional, sem mobilizar os recursos necessários para a transformação das escolas. Na medida em que o Estado se ausenta do papel de mediação entre capital e trabalho, deixando que o mercado se encarregue de selecionar os profissionais e que estes, por sua vez, se responsabilizem pela sua empregabilidade, fica evidenciado o desamparo do trabalhador. Por outro lado, a ausência de uma forte organização sindical de classe acentua ainda mais o abandono do trabalhador.

As reduções de investimentos do Estado, e a conseqüente queda da qualidade da formação profissional, acarretarão, a longo prazo, conseqüências contrárias aos interesses do capital. Portanto, a formação profissional atual não contempla as novas exigências profissionais, tanto do ponto de vista do mercado de trabalho, como do ponto de vista do trabalhador e nem sob a óptica do capital. Desta forma, a atuação do Estado é imprescindível para a garantia de uma formação de qualidade e para a regulação da sociedade, e talvez o insucesso da reforma tenha sido mais fruto do descomprometimento do Estado em proporcionar as condições necessárias às escolas, do que de qualquer outra razão.

\section{REFERÊNCIAS}

1. Harres, E.; II Seminário de Pesquisa em Educação da Região Sul, 2000, 1 CD ROM

2. Wood Jr., T.; Revista de Administração de empresas/EAESP/FGV, São Paulo, 1992, 7 .

3. Antunes, R.; Os Sentidos do Trabalho Ensaio sobre a afirmação e negação do Trabalho, Coleção Mundo do Trabalho; Boi tempo: São Paulo, 1999.

4. Althusser, L.; Sobre a Reprodução, Ed. Vozes: Petrópolis, 1999.

5. http://www.ministeriodotrabalho.gov.br, acessada em Dezembro 2000.

6. Poulantzas, N.; O Estado, o Poder, o Socialismo, Graal: Rio de janeiro, 1983.

7. Kuenzer, A., org.; Ensino Médio: construindo uma proposta para os que vivem do trabalho, Cortez: São Paulo, 2000.

8. Kuenzer, A.; Ensino Médio e Profissional: as políticas do Estado neoliberal, 2a ed., Cortez: São Paulo, 2000 (Coleção Questões de Nossa Época, vol. 63).

9. Garcia, S. R. de O.; II Seminário de Pesquisa em Educação da Região Sul, 2000, 1 CD ROM.

10. Machado, L. R. de S.; Educação e Divisão social do trabalho: contribuição para estudo do ensino técnico industrial brasileiro, $2^{\mathrm{a}}$ ed.; Cortez: São Paulo, 1989

11. Siqueira, M. D.; Curso de Química: 60 anos de História, Setor de Ciências Exatas, Departamento de Química-UFPR, Curitiba, 1999.

12. Lei de Diretrizes e Bases da Educação Nacional [LDB n9394/96], de 20 de dezembro de 1996, Diário Oficial da República Federativa do Brasil, em 23 de dezembro de 1996.

13. Leite, E. M.; Texto elaborado para o "Seminário sobre Educación para el mundo del trabajo y lucha contra la pobreza”, promovido pela UNESCO, IIEP e INET-Argentina, em Buenos Aires, nov/95 (para publicação nos anais do Seminário).

14. Programa do Ensino Técnico em Química do Instituto Politécnico Estadual, Curitiba-PR, 1995

15. Decreto Federal no 2208, de 17/04/1997: Regulamentação do Parágrafo do Art.36 e os Arts. 39 a 42 da Lei n9394/96.

16. Silva, J. M. A. de P.; Quim. Nova 2001, 24, 135.

17. Marx, K.; A Ideologia Alemã, $1^{\text {a }}$ ed.; Martins Fontes: São Paulo, 1989.

18. Marx, K.; O Capital: crítica da economia política: livro I, $17^{\mathrm{a}}$ ed.; Civilização Brasileira: Rio de Janeiro, 1999.

19. Vasques, A. S.; Filosofia da Práxis, $2^{\mathrm{a}}$ ed.; Paz e Terra: Rio de janeiro, 1977.

20. http://www.sinquirs.org.br, acessada em Outubro 2003

21. http://www.sinquisp.org.br, acessada em Outubro 2003 